\title{
Preface for the Special Issue of ISGMA 2014
}

\author{
Guest Editors: Jaehwan Kim', Won-Shik Chu², and Sung-Hoon Ahnn ${ }^{2,3, \#}$ \\ 1 Department of Mechanical Engineering, Inha University, 100, Inha-ro, Nam-gu, Incheon, 402-751, South Korea \\ 2 School of Mechanical and Aerospace Engineering, Seoul National University, 1 Gwanak-ro, Gwanak-gu, Seoul, 151-742, South Korea \\ 3 Institute of Advanced Machinery and Design, Seoul National University, 1 Gwanak-ro, Gwanak-gu, Seoul, 151-742, South Korea \\ \# Corresponding Author / E-mail: ahnsh@snu.ac.kr, TEL: +82-2-880-7110, FAX: +82-2-888-9073
}

Our societies face several open challenges in the near future, for example, producing sufficient amounts of clean energy from renewable resources, designing new technologies that enable a sustainable economic growth, addressing some relevant environmental issues like quality of air and water or waste recycling, improving our standard of life via more accurate diagnostic tools and new medical treatments. Most of these challenges deal with the design and manufacturing. Environmentally friendly manufacturing is one of industry's greatest strategic challenges, not only from a technological perspective, but also from a business and marketing perspective. Many large, multinational companies aware of impending overseas environmental regulations and growing consumer demand for a new generation of environmentally friendly products, and they are striving to prepare their solutions. Many manufacturers have recognized that green products and green production techniques can be their competitiveness.

Thus, sustainability is important in next generation of manufacturing technology. Next generation manufacturing technology should be able to reduce human and ecological risks, enhance cost effectiveness, improve process efficiency, and create products and processes that are environmentally beneficial. Green manufacturing is to prevent pollution and save energy through the discovery and development of new knowledge that reduces and/or eliminates the use or generation of hazardous substances in the design, manufacture, and application of chemical products or processes. Whole life cycle cost of manufacturing should include environmental impact, energy, material and resource reuse, end of life, re-use, re-manufacturing, societal costs, manufacturing impacts and supply chain impacts. Thus, there are a lots of challenges and opportunities in green manufacturing.

The International Symposium on Green Manufacturing and Application (ISGMA) 2014 held in Busan, Republic of Korea, June 2428, 2014, was all about green manufacturing technologies and its applications. The ISGMA 2014 provided the presentations of the stateof-the-art research, development, and innovative advances of green manufacturing and fostered relevant discussions on energy conversion, system efficiency, pollution and waste reduction, light and ecofriendly materials, renewable energy systems, and environment management in factories and processes. The symposium facilitated opportunities for researchers and engineers to exchange ideas and knowledge via meetings and discussions.

This Special Issue of International Journal of Precision Engineering and Manufacturing (IJPEM) contains a selection of sixty three articles presented at the ISGMA 2014. This special issue delivers the state-ofthe-art of green manufacturing technologies including lightweight and ecofriendly composite materials, design, manufacturing, improvement of manufacturing efficiency, energy saving, energy harvesting and manufacturing of new renewable energy systems. Emphasis is given to articles addressing design and manufacturing issues in the area of ecofriendly and functional nanocomposite materials, active materials, 3-D printing and hybrid manufacturing.

We would like to express our sincere appreciation to the conference chair, Dr. Hon-Zong Choi of Korean Institute of Industrial Technology, and Professor Beomsoo Kang of Pusan National University for their efforts in organizing the symposium and providing a comfortable environment for the symposium. We also thank all of the authors who attended the symposium for their contributions and especially those who made an additional effort to further expand their articles for this special issue. We are also grateful to the organizing committee members of the symposium for providing the multiple reviews for the articles. We really appreciate their precious time and effort on the review. Lastly, we would like to thank Professor Dae-Eun Kim, Editor-in-Chief of IJPEM and Professor Sun-Kyu Lee, the president of Korean Society for Precision Engineering, for giving us the opportunity to publish this special issue. 